\title{
LINGUA(GEM) E IDENTIDADE: A SURDEZ EM QUESTÃO
}

\author{
Zilda Maria Gesueli*
}

RESUMO: Este trabalho discute o papel da língua de sinais na construção da identidade surda. Diferentes autores têm discutido a relação língua(gem) na construção da identidade, destacando-se que esta se constitui a partir da significação - ao significar o sujeito se significa (Orlandi, 1998). Dessa forma, buscamos trazer esta discussão para o campo da surdez levando em conta que, o interlocutor privilegiado da criança surda é o próprio surdo e o lugar de contato com essa língua se dá, para a maioria dos alunos, dentro das instituições ou escolas especiais para surdos. Observamos que a inserção do professor surdo na sala de aula contribui para que os alunos não somente encontrem possibilidades de construção da narrativa em língua de sinais, mas também se percebam como surdos, construindo sua identidade já na idade de 5-7 anos, assumindo e diferenciando papéis na interação, principalmente em relação ao professor surdo e ao professor ouvinte. A perspectiva de educação bilíngüe na área da surdez está antecipando a consciência dos próprios surdos sobre o significado da surdez, o que há bem pouco tempo acontecia somente na idade adulta.

Palavras-chave: Linguagem. Surdez. Identidade. Língua de sinais.

\section{LANGUAGE AND IDENTITY: DEAFNESS IN QUESTION}

ABSTRACT: This paper approaches the role of sign language in the construction of deaf identity. Various authors have discussed how language relates to the construction of identity, pointing out that identity constitutes through meaning - when a subject means they becomes meaningful (Orlandi, 1998). We thus attempt to link this discussion

* Doutora em Psicologia da Educação pela Faculdade de Educação da Universidade Estadual de Campinas (Unicamp) e professora do Centro de Estudos e Pesquisas em Reabilitação "Prof. Dr. Gabriel Porto” (CEPRE/FCM) da UNICAMP. E-mail: zgesueli@fcm.unicamp.br

Disponível em <http://www.cedes.unicamp.br> 
Lingua(gem) e identidade: a surdez em questão

to the field of deaf studies, considering that in the case of deaf children the privileged interaction partner is another deaf person. Most students have their first contact with this language in schools and institutions for the deaf. We have observed advantages when deaf teachers take over classroom teaching: one is that students are able to develop narrative constructions in sign language; another one is that this experience enables them to perceive themselves as deaf, and construct a deaf identity as early as 5-7 years., when they take on and differentiate roles in interaction, especially with regard to the deaf teacher and the hearing teacher. In the field of deafness, the bilingual education approach anticipates deaf people's awareness of the meaning of deafness, which until quite recently was occurred in adulthood.

Key words: Language. Deafness. Identity. Sign language.

\section{Introdução}

E ste trabalho pretende discutir aspectos da relação linguagem/ identidade enfocando a área da surdez, a qual tem se constituído no campo de minha atuação profissional no decorrer desses anos.

O contato com crianças surdas pré-escolares no Centro de Estudos e Pesquisas em Reabilitação "Prof. Dr. Gabriel Porto", pertencente à Faculdade de Ciências Médicas da Universidade Estadual de Campinas - Brasil (doravante CEPRE), suscitou meu interesse para as possibilidades de construção da identidade surda, principalmente em decorrência da implantação da proposta de educação bilíngüe que teve início por volta do ano de 1991, marcada pela inserção do professor surdo na sala de aula.

Tendo passado pelas diferentes correntes educacionais como oralismo e comunicação total, o CEPRE iniciou o processo de reflexão e adesão ao ensino bilíngüe buscando a oficialização da língua de sinais em sala de aula, privilegiando o papel do professor surdo neste processo.

Essa abordagem traz, fundamentalmente, uma nova concepção de surdez, que implica mudanças ideológicas, rompendo de fato com a concepção oralista e em grande parte com os sistemas da comunicação total, que não propiciaram alterações significativas no que se refere à importância da língua de sinais e ao papel da comunidade surda no processo educacional. 
A proposta de educação bilíngüe sugere-nos, então, mudanças que se mostram necessárias, sendo a mais importante delas o respeito à língua de sinais como língua natural ${ }^{1}$ e de direito do surdo. Outra mudança refere-se à condição bilíngüe do surdo, ou seja, ele deverá ter acesso à língua de sinais por meio do contato com a comunidade surda (dado o fato de $95 \%$ dos surdos serem filhos de pais ouvintes e adquirirem tardiamente a língua de sinais), possibilitando que a língua majoritária, oral e escrita, seja trabalhada como segunda língua. Portanto, o surdo deverá ser bilíngüe. "O modelo bilíngüe parte do reconhecimento de que os surdos estão em contato com duas línguas e que uma destas línguas é a língua de sinais" (Sanchez, 1991, p. 4). E "quando o bilingüismo afirma que as línguas de sinais dos surdos são línguas naturais, reivindica para a Língua de Sinais o mesmo status lingüístico de todas as línguas naturais" (idem, ibid., p. 6).

Nessa perspectiva, a aceitação de uma língua implica sempre a aceitação de uma cultura, conforme lembra Behares (1993). Para este autor, a passagem para a educação bilíngüe significa uma mudança ideológica com respeito à surdez e não uma mudança meramente metodológica. Afirma que a educação bilíngüe se propõe a transformar a educação dos surdos em uma pedagogia socializada, abandonando as práticas clínicas e terapêuticas, o que parece vir ao encontro do pensamento de Vygotsky: "Na psicologia, o problema da criança deve ser apresentado e compreendido como um problema social, porque o aspecto social, antigamente diagnosticado como secundário e derivado, de fato é o fator principal e primário" (Vygotsky, 1989a).

De acordo com a concepção socioantropológica, a surdez é compreendida como experiência visual (Skliar, 1999), desestabilizando idéias preconcebidas sobre a chamada normalidade. Tal experiência visual, segundo o autor, não é restrita a uma capacidade de produção e compreensão especificamente lingüística ou a uma modalidade singular de processamento cognitivo, mas que se traduz em todos os tipos de significações, representações e/ou produções do surdo, seja no campo intelectual, lingüístico, ético, estético, artístico, cognitivo, cultural etc. ${ }^{2}$ Faz-se necessário, então,

um modelo no qual o déficit auditivo não cumpra nenhum papel relevante, um modelo que se origine e se justifique nas interaçôes normais e habituais dos surdos entre si, no qual a língua de sinais seja o traço fundamen-

Educ. Soc., Campinas, vol. 27, n. 94, p. 277-292, jan./abr. 2006 
tal de identificação sociocultural e no qual o modelo pedagógico não seja uma obsessão para corrigir o déficit mas a continuação de um mecanismo de compensação que os próprios surdos, historicamente, já demonstraram utilizar. (Skliar, 1997, p. 140).

A questão da língua de sinais, portanto, está intimamente relacionada à cultura surda. Esta, por sua vez, remete à identidade do sujeito que (con)vive, quase sempre, com as duas comunidades (surda e ouvinte). Neste contexto, importa analisar o modo que os sujeitos inseridos em escolas bilíngües se narram como sujeitos da comunidade surda. Assim, o papel do professor surdo e da língua de sinais no ambiente escolar é essencial para que haja construção da identidade surda e, conseqüentemente, para chegarmos a uma educação eficiente.

O presente artigo discute as mudanças que ocorreram na instituição anteriormente citada após a inserção do professor surdo em sala de aula, atuando conjuntamente com o professor ouvinte. A seguir apresento os pressupostos teóricos e os dados que sustentam a discussão.

Língua de sinais, cultura e identidade

Recorrendo aos fundamentos da teoria histórico-cultural, estarei olhando para a criança surda na qualidade de sujeito interativo, que se constitui nas relações sociais. Meu interesse está na análise do jogo intersubjetivo e não apenas na ação da criança. Esse interesse também não implica examinar apenas a atuação de outros diante da criança, sendo necessário enfatizar que, conforme lembra Góes (1991, p. 19), "o plano intersubjetivo não é o plano do 'outro', mas o da relação do sujeito com o outro".

Vygotsky (1981, 1984, 1989a, 1989b, 1993) concebe o homem como um ser sociocultural, afirmando que seu desenvolvimento se dá inicialmente no plano intersubjetivo (das relaçóes sociais) e depois no plano intra-subjetivo (envolvendo o processo de internalização). No desenvolvimento assim concebido, a linguagem terá um papel fundamental, como mediadora das interações e da significação do mundo, ou ainda, a concepção de que o sujeito não significa o mundo para, a partir de então, representá-lo pela linguagem, mas, sim, que essa significação se constrói também pela própria linguagem. 
Assim, para Vygotsky, a relação do homem com o mundo não é direta, mas mediada, e as ocorrências de mediação primeiramente vão emergir de outrem e depois vão orientar-se ao próprio sujeito. Portanto, "a dimensão significativa da mediação semiótica é também afirmada quanto à relação do homem consigo próprio" (Góes, 1994, p. 95) e essa relação não é direta, mas mediada pelo signo.

Esta afirmação leva à constatação de que o desenvolvimento do reconhecimento do Eu é um processo semiótico, que pressupõe a participação de outras pessoas (visto que a atividade com signos é necessariamente interpessoal). Desse modo, as relaçôes sociais constituem-se por intermédio dos processos semióticos e a construção da identidade só poderá ser examinada considerando-se a dinâmica de significados e sentidos produzidos e interpretados no jogo interativo do sujeito com o outro (Góes, 1998).

Nesta proposição, quando falamos em indivíduo que interage com seu meio e absorve de maneira particular a cultura e os valores desse meio, estamos admitindo, necessariamente, o processo de internalização, que irá ocorrer no contexto das interações sociais, a partir da atividade mediada.

Dado o papel da linguagem como atividade constitutiva (Franchi, 1977), interessa-nos discutir a relação língua(gem)/identidade, entendendo que o sujeito se constitui como tal à medida que interage com os outros. Parafraseando Geraldi (1996), a língua e o sujeito constituem-se nos processos interativos. "Isto implica que não há um sujeito dado, pronto, que entra em interação, mas um sujeito se completando e se construindo nas suas falas e nas falas dos outros" (idem, ibid., p. 19).

Ainda outros autores têm discutido a relação língua(gem) na construção da identidade, destacando-se que ela se constitui a partir da significação. Destacamos o trabalho de Orlandi (2001), que ao tratar da identidade lingüística vista no cotidiano da vida escolar releva que: 1) a identidade é um movimento na história; 2) ao significar, o sujeito significa-se; 3) a identidade não resulta de processos de aprendizagem, mas refere-se a posições que se constituem em processos de memória afetados pelo inconsciente e pela ideologia; 4) os processos de significação são constituídos por um deslize que se dá em redes de filiações históricas (cf. Pêcheux, 1983, apud Orlandi, 2001), sendo, desse modo, ao mesmo tempo, repetição e deslocamento. 
Estaremos nos detendo nas afirmações 2 e 3 , as quais nos interessam na perspectiva do sujeito surdo, especialmente aqueles filhos de pais ouvintes, levando em conta que o interlocutor privilegiado da criança surda é o próprio surdo.

Se o tema da linguagem na construção da identidade deve ser considerado no processo educacional de qualquer sujeito, mais significativo ele se torna na questão da surdez, pois em razão do uso da língua de sinais a criança surda filha de pais ouvintes, possivelmente, terá poucas oportunidades de usar significativamente essa língua. Em outras palavras, as possibilidades de aquisição da língua de sinais estarão restritas ao contato com a comunidade surda.

Essa aquisição poderá ocorrer tardiamente, na relação com iguais na escola especial ou em instituições para surdos ou ainda no contato com a comunidade surda (nas igrejas e nas associaçóes de surdos). A criança surda filha de pais surdos (o que se constitui em uma pequena minoria) poderá adquirir a língua de sinais na interação com seus pares, análogo ao que ocorre com a criança ouvinte.

Se o vínculo entre a língua e a vida é tão forte como nos diz Bakhtin (1952-1953/1992), afirmando que por meio dos enunciados concretos a língua penetra na vida e vice-versa, o que acontecerá à criança surda filha de pais ouvintes, que costuma ter pouca participação nas práticas sociais mediadas pela língua de sinais?

Se ao significar nos significamos, isto é, sujeito e sentido configuram-se e é nisso que consistem os processos de identificação (Orlandi, 2001), como os surdos filhos de pais ouvintes estarão construindo a identidade surda se estes não possuem acesso à língua de sinais?

Se identidade não resulta de processos de aprendizagem, mas constitui-se em um movimento na história, como os surdos estão significando o mundo? Será que eles estão sendo inseridos nesse jogo entre a língua e a história que nos leva a produzir sentidos e, conseqüentemente, a nos constituirmos como sujeitos?

De acordo com Souza (1998), mesmo os surdos oralizados passam a fazer uma leitura de mundo somente a partir do uso da língua de sinais e, antes disso, suas possibilidades de participar ativamente com e na comunidade ouvinte são bastante reduzidas. Disso decorre uma identidade "fragmentada": o surdo que não domina a língua de sinais não se identifica com o grupo de surdos, tampouco se identifica 
com o mundo ouvinte, pois lhe falta vivência na língua majoritária que, de certa forma, sempre esteve pautada em exercícios e práticas artificiais (língua transformada em código).

Estas são algumas indagações que acredito serem relevantes para uma discussão entre pesquisadores da área da surdez com o objetivo de refletir sobre o papel do professor surdo e, conseqüentemente, da língua de sinais na construção da identidade surda.

Estaremos utilizando o conceito de identidade a partir da discussão de Hall (1997, apud Perlin, 1998), que considera três diferentes conceitos de identidade presentes na História: o iluminista, o sociológico e o da modernidade tardia ou pós-modernidade. $\mathrm{O}$ conceito de identidade pós-moderna é o que será utilizado neste trabalho. Perlin (1998, p. 52) reinterpreta Hall, tratando esse conceito como resultante de: "Identidades plurais, múltiplas; que se transformam, que não são fixas, imóveis estáticas ou permanentes, que podem até mesmo ser contraditórias". Algo em construção, em movimento e que empurra o sujeito em diferentes posições.

Com base nesta concepção de identidade consideraremos, então, identidade surda como sendo reprimida dentro da cultura ouvinte; ela está "sempre em proximidade, em situação de necessidade com o outro igual. O sujeito surdo nas suas múltiplas identidades sempre está em situação de necessidade diante da identidade surda" (Perlin, op. cit., p. 53).

Assim, para que a construção da identidade surda aconteça é essencial o encontro surdo-surdo, pois temos observado, nesses anos de interação professor ouvinte/professor surdo, que o interlocutor privilegiado da criança surda é o próprio surdo.

Faz-se necessário ressaltar que a surdez não é homogênea, ou seja, o grupo de surdos não é uniforme. Dentro do que denominamos surdos, fazem parte os surdos das classes populares, as mulheres surdas, os surdos negros, surdos de zona rural, entre outros (Skliar, 1998).

Assim, temos os surdos oralizados que não consideram necessária a oficialização da língua de sinais e, em contrapartida, os surdos filhos de pais surdos, usuários da língua brasileira de sinais (LIBRAS), e que não se consideram deficientes auditivos.

Enfim, podemos considerar a possibilidade de múltiplas identidades surdas, ou seja, elas são heterogêneas e apresentam diferentes facetas. Perlin (1998) vai além, classificando a identidade surda em cin- 
co grupos: 1) identidade surda: aquela que cria um espaço cultural visual dentro de um espaço cultural diverso, ou seja, recria a cultura visual, reivindicando à História a alteridade surda; 2) identidades surdas híbridas: aquelas de surdos pós-locutivos, que nasceram ouvintes e se tornaram surdos; 3) identidades surdas de transição e formadas por surdos que viveram sob o domínio da cultura ouvinte (em geral, os surdos oralizados) e que posteriormente são inseridos na comunidade surda (processo de "des-ouvintização" 3 da representação da identidade); 4) identidade surda incompleta: aquela dos surdos que vivem sob o domínio da cultura ouvinte e negam a identidade surda; 5) identidades surdas flutuantes, formadas por sujeitos surdos que reconhecem ou não sua subjetividade, mas que desprezam a cultura surda, não se comprometendo com a comunidade.

Dentro desta perspectiva a discussão sobre identidade surda não está desvinculada da cultura surda, a qual estaria relacionada ao processo de recriação de um espaço cultural visual. Na medida em que os surdos legitimam sua língua e sua comunidade, temos como decorrência dessa convivência minoritária o nascimento da cultura surda (arte, humor, teatro, poesia etc.). "É necessário manter uma posição intercultural mesmo que seja de riscos. A identidade surda se constrói dentro de uma cultura visual. Essa diferença precisa ser entendida não como uma construção isolada, mas como construção multicultural" (Perlin, op. cit.).

\section{Algumas considerações do contexto de sala de aula}

Atuando com crianças surdas na faixa etária de 4-7 anos, tenho observado mudanças nesse contexto decorrentes da inserção do professor surdo na sala de aula. O contato com o adulto surdo de forma sistematizada tem propiciado novas atitudes dos alunos com relação à imagem e ao papel de cada participante do grupo.

Inicialmente pudemos observar entre os interlocutores um jogo de correções e ajuda, próprio do jogo da linguagem, sobre o uso da língua de sinais, estabelecendo-se, assim, novas imagens sobre os diferentes interlocutores (os que dominam e os que não dominam a língua de sinais). Muitas vezes o professor ouvinte (papel também desempenhado por mim, autora deste artigo) fazia trocas no uso de sinais por ter um conhecimento "dicionarizado" da língua e, portanto, não fluente. Assim, a professora ouvinte tem dificuldades para articular a polissemia 
da língua que domina - o português - e as possibilidades de "tradução" para a língua que utiliza com menor fluência - a de sinais (para uma discussão mais aprofundada, ver Gesueli, 1998). Diferentemente, o professor surdo é considerado um expert, um locutor privilegiado, cabendo a ele julgar o certo ou o errado no uso dos sinais.

É comum o aluno corrigir os sinais utilizados por integrantes do grupo (surdos e ouvintes) e, não raro, fazer consultas ao professor surdo. Essa interdependência ${ }^{4}$ evidente dos professores também contribui para o fato de o professor surdo ser considerado "a referência" para o uso da língua; ou seja, a língua de sinais é tarefa e esfera de competência do professor surdo.

Ocorrências importantes que tenho observado na sala de aula mostram as correçôes que as crianças fazem dos enunciados da professora ouvinte e dos parceiros, reafirmando o fato de que, numa situação sociolingüística semelhante a essa, o interlocutor privilegiado do aluno surdo é o próprio surdo.

Sendo assim, a criança vai tomando a própria língua de sinais como objeto de atenção, participando de negociações que focalizam a adequação dos interlocutores, e sua competência lingüística evolui em íntima relação com os enunciados do outro, que se realizam nas interações face a face (parceiros ou professora) ou que são ecoados no dizer de cada sujeito (ecos do dizer de outros não presentes, em especial do professor surdo). "Nossos enunciados (...) estão repletos de palavras dos outros, caracterizadas, em graus variáveis, pela alteridade ou assimilação. (...) As palavras dos outros introduzem sua própria expressividade, seu tom valorativo, que assimilamos, reestruturamos, modificamos" (Bakhtin, 1952-1953/1992, p. 313).

Esse "outro" surdo passa a ser diferenciado pelo grupo de alunos, propiciando a constituição do sujeito surdo por meio do exercício da língua de sinais. É nesse processo de legitimação da língua que a identidade se constrói. Veja-se, como exemplo, o seguinte episódio:

"Após o intervalo, os alunos entraram para a sala e sentaram-se à mesa de trabalho. A professora ouvinte tenta chamar a atenção dos alunos em vão, que continuam em intensa interação. Considerando a possibilidade de o conteúdo escolar não ser de interesse das crianças, a professora ouvinte procura entrar na conversa e os alunos sinalizam sugerindo que ela espere alguns momentos: afinal encontravam-se muito ocupados!" 
O exemplo acima revela o jogo de imagens que vão se compondo na relação professor ouvinte/aluno surdo. A professora deixa de ter lugar de predomínio no controle das interlocuções e tem dificuldade, nesse contexto, de legitimar a sua fala, quando o grupo está às voltas com uma prática de linguagem particular, que, ao que parece, não diz respeito ao interlocutor ouvinte. Aqui, a língua de sinais, portanto, exclui o professor ouvinte.

Este fato evidencia a importância da língua de sinais no processo de construção da identidade. Assim, o papel do professor ouvinte é discutir as características lingüísticas e político-sociais das diferentes línguas - português e língua de sinais.

A partir do momento em que os alunos começam a vivenciar diferencialmente estas línguas - português e língua de sinais - e a perceber que cada uma delas possui seu valor e sua função, eles se identificam como grupo usuário da língua de sinais, considerando o professor ouvinte, muitas vezes, fora desse grupo.

Temos observado, então, que o reconhecimento de sua condição surda começa a aparecer em crianças na idade de 5-6 anos. Antes do contato com o surdo adulto esse reconhecimento se dava tardiamente ou nem chegava a acontecer.

Outro episódio que merece atenção diz respeito ao depoimento de mães sobre a solicitação constante das crianças a respeito do que está sendo dito na TV e que elas não possuem acesso. Atualmente, os alunos reivindicam muito mais de seus familiares uma explicação sobre o diálogo presente em desenhos e novelas, em geral. Os alunos já compreendem a necessidade de uma tradução para a língua de sinais daquilo que está sendo televisionado.

Essa solicitação por parte de um de nossos alunos foi de forma tão insistente que a mãe, já impaciente, pediu que a criança esperasse uns instantes. Rapidamente, a criança respondeu em sinais que a mãe deveria ser compreensiva, pois ela era surda e não tinha acesso ao texto oralizado.

A mãe relatou o episódio à professora com muita surpresa, pois ela própria nunca havia discutido com a filha sobre a sua surdez. Portanto, nunca haviam "verbalizado" a questão que muito provavelmente surgiu a partir da interação com adultos surdos na instituição.

Acreditamos que o contato das crianças com professores surdos desde muito cedo possibilita o uso efetivo da língua de sinais e dá pers- 
pectivas de tornar-se um sujeito pertencente à comunidade surda. Os alunos têm demonstrado um certo amadurecimento sobre questóes de identidade, aceitando-se como tais, apesar das inúmeras possibilidades de ouvintização a que estão sujeitos.

\section{(Re)conhecendo a surdez}

Com a intenção de mostrar o significado da língua de sinais no processo de construção da identidade surda, meu objetivo foi o de apontar alguns indícios de mudança nas interações em sala de aula e fora dela, decorrentes da sistematização do uso da língua de sinais a partir da inserção do professor surdo nas interações diárias.

Garantir o uso da língua de sinais no contexto escolar parece primordial para que haja reconhecimento da surdez, pois é por intermédio da linguagem que significamos o mundo e conseqüentemente nos significamos.

Vale ressaltar que as interaçôes, a relação com o outro, nem sempre se dá de forma harmoniosa. Em Smolka et al. (1995) encontramos uma discussão sobre a intersubjetividade - a constituição do sujeito nas relações sociais -, na qual esses autores vão questionar a idéia de harmonia na essência desse processo, já que oposiçôes e confrontos fazem parte do funcionamento mesmo de sujeitos em interação.

As possibilidades de relação eu-outro são complexas (e mesmo entre parceiros, nem sempre simétricas), porque a linguagem é "desarrumada", não é transparente e, na concepção bakhtiniana, polissêmica e polifônica. Portanto, a discussão sobre o processo intersubjetivo implica um aprofundamento sobre a constituição do sujeito na relação, considerando que este não é dado, não está pronto, mas que ao interagir se completa e se constrói na sua fala e na fala do outro.

As atividades lingüísticas decorrentes da interação em sala de aula, sejam com o professor ouvinte ou com o professor surdo, são conseqüências da mediação do outro e dos jogos de imagem que as crianças estão exercendo, pois

no embate das relações interlocutivas, a construção dos modos de ver o mundo não é sempre harmônica. Ainda que os interlocutores possam compartilhar algumas de suas crenças, sempre se está reorganizando, pelos dis- 
Lingua(gem) e identidade: a surdez em questão

cursos, as representações que fazem do mundo dos objetos, de suas relações e das relações dos homens com o mundo entre si. (Geraldi, 1993, p. 27).

Assim, uma vez que a fala se realiza entre os homens, as açóes que praticamos pela linguagem incidem sempre sobre o outro, pois por meio delas representamos, e apresentamos a nossos interlocutores uma certa construção da realidade, para com isso interferirmos sobre seus julgamentos, opiniōes, preferências.

Essas reflexôes e o contato com a comunidade surda me levam a afirmar a importância da língua de sinais na constituição da identidade surda e no trabalho educacional, na certeza de que esse trabalho só terá frutos se contar com a participação do professor surdo fluente nessa língua. O professor ouvinte, desde que fluente na língua de sinais, muito poderá também contribuir para esse processo.

Apesar de estarmos em meio a um processo de aquisição de língua de sinais, pautado em condiçôes não totalmente satisfatórias, as crianças estão criando com a língua e se constituindo como sujeitos surdos, o que reforça o argumento de que

não há nada imanente na linguagem salvo sua força criadora e constitutiva (...). A linguagem, pois, não é um dado ou resultado; mas um trabalho que 'dá forma' ao conteúdo variável de nossas experiências, trabalho de construção, de retificação do 'vivido', que ao mesmo tempo constitui o sistema simbólico mediante o qual se opera sobre a realidade e constitui a realidade como sistema de referências em que aquele se torna significativo. Um trabalho coletivo em que cada um se identifica com os outros e a eles se contrapóe, seja assumindo a história e a presença, seja exercendo suas opções solitárias. (Franchi, 1977, p. 22)

Vale reafirmar que a presença do professor surdo contribui expressivamente para que as crianças adquiram a língua de sinais e passem a identificar-se com este sujeito que apresenta um papel de destaque na sala de aula. Esta convivência possibilita não só o reconhecimento da identidade surda, mas a identificação política e social com essa comunidade, pois é preciso trazer para a sala de aula a história da comunidade surda, de suas lutas e vitórias.

Como já mencionamos anteriormente, o trabalho de Souza (1998) traz depoimentos de surdos adultos que alegam ter aprendido a discutir sobre coisas triviais do cotidiano, ou sobre assuntos que de- 
pendiam de conhecimentos sistematizados, somente quando aprenderam a língua brasileira de sinais. Assim, por exemplo, uma moça surda, depois de ter adquirido a língua de sinais, dizia de sua experiência de aprendizagem da fala: "Eu era oralizada mas não tinha aquele vocabulário (...) parece meio frio, igual papagaio, (...) saber falar mas não saber conversar, então eu repetia tudo" (Souza, 1998, p. 33).

Esses depoimentos indicam a importância da convivência de crianças surdas, principalmente as filhas de pais ouvintes, com a comunidade de surdos, para que elas possam constituir-se como sujeitos. Não podemos correr o risco de que, como nos aponta Góes (1998), o aluno venha a equivaler surdez com incapacidade, em conseqüência das insuficientes experiências no uso de sinais.

Assumir a identidade surda é ainda um processo complexo para muitos surdos pois isso significa assumir a própria condição de surdez e o compromisso de pertencer a um grupo minoritário e, infelizmente, ainda muito discriminado.

Podemos observar que o contato com a comunidade ouvinte e as dificuldades que esta interação pode representar (em razão do desconhecimento da língua de sinais e das conseqüências da surdez) podem vir a contribuir para que os surdos reconheçam e assumam a sua identidade.

O contato quase diário com uma surda pós-locutiva (que perdeu a audição na idade adulta) tem me propiciado a reflexão sobre essas questôes. Vejamos o que ela diz:

"Eu não tenho mais vontade de participar de reuniōes de família, eu não consigo entender nada do que eles falam. Eles falam tudo muito rápido, eu pego algumas palavras e, quando tento checar com meu marido, percebo que a minha dedução está completamente equivocada. Fico sem graça de ficar perguntando e pedindo para repetir, é chato! (...) Não adianta, eu já cansei de explicar que eu sou surda. Eles não entendem!"

O fato de ela ser oralizada e falar bem com o ouvinte parece não favorecer sua condição de "surda", o que, até certo ponto, dificulta sua interação com familiares ouvintes.

Isso mostra que a interação com o "reverso", ou seja, com o que não sou (representado pelo grupo majoritário), também impulsiona o reconhecimento do que sou, isto é, a minha identidade. ${ }^{5}$ Não se pode negar que a comunidade ouvinte possui também o seu papel na construção

Educ. Soc., Campinas, vol. 27, n. 94, p. 277-292, jan./abr. 2006

Disponível em <http://www.cedes.unicamp.br> 
da identidade surda. A alteridade no mundo capitalista tem um estatuto quase biológico, que deve ser transformado politicamente. $\mathrm{O}$ reconhecimento da diferença, nesse sistema, não implica sua aceitação (Pêcheux, 1981, apud Orlandi, 2001). Para Orlandi (op. cit.), a língua faz parte desse "valor":

O reconhecimento e o investimento no apagamento da diferença, numa sociedade como a nossa, fazem parte disso que estou chamando movimento da identificação. Como tenho dito insistentemente, onde há censura (apagamento), há resistência, migração de sentidos, transferências obrigadas. (Orlandi, 2001, p. 205)

$\mathrm{Na}$ tentativa de apagar a surdez, ela própria se fortaleceu e a prática em língua de sinais tornou-se pública. O surdo tem, até hoje, vivido um movimento de resistência, buscando o reconhecimento de sua cultura, tentando fazer-se presente como minoria lingüística, mesmo que ainda fragmentado e dividido pelo grupo que se submete à hegemonia cultural.

Recebido em agosto de 2005 e aprovado em novembro de 2005.

Notas

1. Estou considerando a língua de sinais uma língua natural, com características próprias de uma língua natural qualquer e não no sentido de inato ou de língua universal.

2. Skliar significa a surdez com base em quatro níveis diferenciados, porém politicamente interdependentes: como diferença política, como experiência visual, caracterizada por múltiplas identidades, e, finalmente, localizada dentro do discurso da deficiência (Skliar, 1999).

3. Ouvintismo é um termo utilizado por Skliar (1998) e definido como sendo um conjunto de representações dos ouvintes sobre a surdez e sobre os surdos, a partir do qual o surdo estará obrigado a olhar-se e a narrar-se como se fosse ouvinte. Daí decorrem as percepções do ser deficiente, as quais legitimam as práticas terapêuticas habituais.

4. Interdependência porque o professor surdo é usuário fluente da língua de sinais e o professor ouvinte é responsável pelo conteúdo educacional que se desenvolve com o apoio do primeiro.

5. A idéia do "reverso" é uma das idéias e dos conceitos que venho discutindo em parceria com Fernanda M. P. Freire, pesquisadora do Núcleo de Informática na Educação (NIED), da UNICAMP.

\section{Referências bibliográficas}

BAKHTIN, M. Os gêneros do discurso. In: Bakhtin, M. Estética da criação verbal. Trad. de Maria Hermantino Galvão Gomes Pereira. São 
Paulo: Martins Fontes, 1992. p. 277-289. (Texto escrito em russo entre 1952-1953)

BEHARES, L.E. Nuevas corrientes en la educación del sordo: de los enfoques clínicos a los culturales. Cadernos de Educação Especial, Santa Maria, v. 1, n. 4, p. 20-53, 1993.

FRANCHI, C. Linguagem: atividade constitutiva. Almanaque - Cadernos de Literatura e Ensaio, São Paulo, n. 5, p. 9-27, 1977.

GERALDI, J.W. Portos de passagem. 2. ed. São Paulo: Martins Fontes, 1993.

GERALDI, J.W. Linguagem e ensino: exercícios de militância e divulgação. Campinas: Mercado de Letras/ALB, 1996.

GESUELI, Z.M. A criança surda e o conhecimento construído na interlocução em língua de sinais. 1998. 167f. Tese (Doutorado) - Faculdade de Educação, Universidade Estadual de Campinas, Campinas.

GÓES, M.C.R. A natureza social do desenvolvimento psicológico. Caderno CEDES, Campinas, n. 24, p. 17-24, 1991.

GÓES, M.C.R. A linguagem escrita de alunos surdos e a comunicação bimodal. 1994. 197f. Tese (Livre-docência) - Faculdade de Educação, Universidade Estadual de Campinas, Campinas.

GÓES, M.C.R. Subjetividade, linguagem e inserção social: examinando processos de sujeitos surdos. Trabalho apresentado VII Simpósio de Pesquisa e Intercâmbio Científico - ANPEPP, Gramado-RS, 1998.

HALL, S. Identidades culturais na pós-modernidade. Rio de Janeiro: DP\&A, 1997.

ORLANDI, E.P. Identidade lingüística escolar. In: SignORINI, I. (Org.). Lingua(gem) e identidade: elementos para uma discussão no campo aplicado. Campinas: Mercado de Letras, 2001.

PÊCHEUX, M. O discurso: estrutura ou acontecimento. Campinas: Pontes, 1993.

PERLIN, G. Identidades surdas. In: SkLIAR, C. (Org.). A surdez: um olhar sobre as diferenças. Porto Alegre: Mediação, 1998.

Educ. Soc., Campinas, vol. 27, n. 94, p. 277-292, jan./abr. 2006 
Lingua(gem) e identidade: a surdez em questão

SANCHEZ, C.M. La educación de los sordos en un modelo bilíngüe. Mérida: Ickonia, 1991.

SKLIAR, C. Uma perspectiva sócio-histórica sobre a psicologia e a educação dos surdos. In: SKLIAR, C. (Org.). Educação e exclusão: abordagens socioantropológicas em educação especial. Porto Alegre: Mediação, 1997. p. 105-153. (Cadernos de autoria, 2)

SKLIAR, C. Os estudos surdos em educação: problematizando a normalidade. In: SkLIAR, C. (Org.). A surdez: um olhar sobre as diferenças. Porto Alegre: Mediação, 1998.

SKLIAR, C. Atualidade da educação bilíngüe para surdos. Porto Alegre: Mediação, 1999.

SMOLKA, A.L.B.; GÓES, M.C.; PINO, A. The constitution of the subject: a persistent question. In: Wertsch, J.V.; Del Rio, P.; Alvarez, A. Sociocultural studies of mind. Cambridge: Cambridge University, 1995. p. 165-183.

SOUZA, R.M. Que palavra que te falta?: lingüística, educação e surdez. São Paulo: Martins Fontes, 1998.

VYGOTSKY, L.S. The genesis of higher mental functions. In: Wertsch, J.V. (Org.). The concept of activity in Soviet psychology. Nova York: M.S. Sharpe, 1981.

VYGOTSKY, L.S. Formação social da mente. São Paulo: Martins Fontes, 1984.

VYGOTSKY, L.S. Fundamentos de defectologia. Havana: Pueblo y Educación, 1989a.

VYGOTSKY, L.S. Concrete human psychology. Soviet Psychology, v. 2, n. 27, p. 53-77, 1989 b.

VYGOTSKY, L.S. Pensamento e linguagem. São Paulo: Martins Fontes, 1993. 